\title{
Post-stroke patients with moderate function have the greatest risk of falls: a National Cohort Study
}

Wycliffe E. Wei ${ }^{1}$, Deirdre A. De Silva ${ }^{2,3+}{ }^{,}$Hui Meng Chang ${ }^{2+}$, Jiali Yao ${ }^{4}$, David B. Matchar ${ }^{5,6,7}$, Sherry H. Y. Young ${ }^{8}$, Siew Ju See ${ }^{2,3}$, Gek Hsiang Lim', Ting Hway Wong ${ }^{3,10^{*+}}$ (D) and Narayanaswamy Venketasubramanian ${ }^{11 \dagger}$

\begin{abstract}
Background: Stroke patients have increased risks of falls. We examined national registry data to evaluate the association between post-stroke functional level and the risk of low falls among post-stroke patients.

Methods: This retrospective cohort study analyzed data from national registries to examine the risk factors for poststroke falls. Data for patients who suffered ischemic strokes and survived the index hospital admission was obtained from the Singapore National Stroke Registry and matched to the National Trauma Registry, from 2011 to 2015. The primary outcome measure was a low fall (fall height $\leq 0.5 \mathrm{~m}$ ). Competing risk analysis was performed to examine the association between functional level (by modified Rankin score [mRS] at discharge) and the risk of subsequent low falls.

Results: In all, 2255 patients who suffered ischemic strokes had recorded mRS. The mean age was 66.6 years and 58.5\% were men. By the end of 2015, 54 (2.39\%) had a low fall while 93 (4.12\%) died.

After adjusting for potential confounders, mRS was associated with fall risk with an inverted U-shaped relationship. Compared to patients with a score of zero, the sub-distribution hazard ratio (SHR) increased to a maximum of 3.42 (95\%Cl:1.21-9.65, $p=0.020$ ) for patients with a score of 2. The SHR then declined to 2.45 (95\%Cl:0.85-7.12, $p=$ 0.098), 2.86 (95\%Cl:0.95-8.61, $p=0.062)$ and 1.93 (95\%Cl:0.44-8.52, $p=0.38)$ for patients with scores of 3,4 and 5 respectively.

Conclusions: An inverted U-shaped relationship between functional status and fall risk was observed. This is consistent with the complex interplay between decreasing mobility (hence decreased opportunity to fall) and increasing susceptibility to falls. Fall prevention intervention could be targeted accordingly.

(263 words)
\end{abstract}

Keywords: Stroke, Falls, Function, Modified Rankin scale

\footnotetext{
*Correspondence: wong.th@doctors.org.uk

${ }^{\dagger}$ Ting Hway Wong and Narayanaswamy Venketasubramanian are joint last authors, having contributed equally.

${ }^{3}$ Duke-NUS Medical School, Singapore, 8 College Road, Singapore 169857,

Singapore

${ }^{10}$ Department of General Surgery, Singapore General Hospital, General

Hospital, Outram Road, Singapore 169608, Singapore

Full list of author information is available at the end of the article
}

(c) The Author(s). 2019 Open Access This article is distributed under the terms of the Creative Commons Attribution 4.0 International License (http://creativecommons.org/licenses/by/4.0/), which permits unrestricted use, distribution, and reproduction in any medium, provided you give appropriate credit to the original author(s) and the source, provide a link to the Creative Commons license, and indicate if changes were made. The Creative Commons Public Domain Dedication waiver (http://creativecommons.org/publicdomain/zero/1.0/) applies to the data made available in this article, unless otherwise stated. 


\section{Background}

Falls are common after strokes, with stroke survivors having an estimated 14\% risk of falling in the first month [1]. Besides injuries, those who fall experience activity limitation, increased dependence, and fear of falling [2]. These form barriers to social and community participation, and negatively impact quality of life [3]. Overcoming these are challenging, as patients require significant cognitive and emotional adjustment to successfully adopt coping strategies [4]. It is thus important to develop effective interventions to reduce risks of a poststroke fall.

Seven major risk factors for falls among community stroke survivors have been identified and in descending order of risk are: impaired mobility, reduced balance, use of psychotropic medications, disability in self-care, depression, cognitive impairment and a history of falls [5]. Several of these are components of functional status which may be a more significant predictor of post-stroke falls. One measure of functional status is the modified Rankin Scale (mRS), which is easily implemented and used in both clinical and stroke trials [6].

Nevertheless, observational studies on the risks of post-stroke falls are limited. Existing studies examining the risks of post-stroke falls in the community are mostly small and cross-sectional in design [7, 8]. Large prospective studies are few. In a systematic review that identified 16 prospective observational studies, half had sample sizes below 100 and only two had a sample size above a thousand [5]. Overall, the evidence may not paint the full picture of the risk factors of falls and stroke, and data on a broad spectrum of stroke patients is needed. Only then can targeted strategies be put in place to reduce the risk of falls and its consequences on the wider stroke population.

Falls captured in trauma registries differ from typical methods used in other observational studies that use self-reports through diary or interview. Trauma registries capture more severe falls that result in presentations for medical care with detailed outcome measures such as the severity and site of injury $[9,10]$. In contrast, studies relying on self-reported outcomes pick up minor and non-injurious falls. For example, a survey of community dwelling elderly showed that $67 \%$ of falls resulted in injuries, with $8.6 \%$ reporting head injuries [11]. Severity of injuries usually cannot be determined in these studies. The use of trauma registries in the study of falls thus provides an additional perspective and information on more severe falls that result in healthcare utilization.

\section{Aim and hypothesis}

This study aims to use nation-wide registry data to evaluate how functional status, as represented by the $\mathrm{mRS}$, is associated with post-stroke falls. We hypothesize that lower mRS, representing milder functional deficits, is associated with reduced risks of fall.

\section{Methods}

This retrospective cohort study analyzed data from national registries to examine the risk factors for poststroke falls. Singaporean patients who survived the index admission for stroke were identified from the National Stroke Registry (NSR). The records were then matched to the National Trauma Registry (NTR) by national identification number and de-identified prior to analysis. For both registries, data between the years 2011 to 2015 was used.

NSR, established in 2002, collects information on stroke cases diagnosed in all public hospitals. NSR is notified of stroke cases through medical claims made to the Singapore Ministry of Health, hospital inpatient discharge summaries and the national death registry. Information collected by the registry (e.g. risk factors and functional outcome scores) is then obtained from medical records and uploaded to the registry in standardised electronic forms [12].

NTR, established in 2011, captures cases that present to emergency departments of all public hospitals with a diagnosis relating to trauma. Information collected include injury severity and outcome measures. Some fields are captured from electronic records automatically while others are collected by data coordinators from the records [10].

The registries are updated with death outcomes by referencing the national death registry. The inclusion criteria, data collection, data cleaning and data quality audit processes of the registries have been described in previous studies $[13,14]$. Only ischemic strokes were included in the main analysis.

\section{Outcome of interest}

The primary outcome was a low fall as captured by the NTR, which is defined by same-level falls or those with fall heights of up to $0.5 \mathrm{~m}$ [10]. The height of fall recorded in the NTR was determined from patient histories based on reference heights (e.g. furniture heights) [10]. Only low-falls were considered as, based on the literature, they are more likely to be related to frailty in contrast to trauma from other injury mechanisms (road traffic injuries, falls from height - e.g. ladders or highrise buildings in urban areas, machinery injury or other blunt mechanisms of injury) which likely have different risk factors and may introduce unnecessary heterogeneity $[10,15,16]$. Event dates in both national registries were matched prior to de-identification, and only poststroke falls were considered. 


\section{Independent variables}

Demographic and clinical variables from the NSR, as well as injury characteristics from the NTR for patients with falls, were used in the analyses. Injury severity was described by the Abbreviated Injury Score (AIS), where a score of three and above represents serious injury. Variables that have been associated with frailty, falls or stroke were included in the analysis. Antiplatelet treatment and anticoagulation at discharge were also included in the model. Post-stroke functional level was measured by the final recorded mRS during the index admission for stroke. Patients without a completed Rankin score were excluded from the main analysis.

\section{Statistical analysis}

Bivariate analysis was performed by using the $t$-test for continuous variables, and the $\chi^{2}$-test or Fisher's Exact test was used for count data. Competing risks analysis, with a low fall as the event of interest and death as the competing event, was performed to evaluate associations with the risk of falls. Data analysis was performed using STATA version 13.0 (Stata Corp, College Station, Tx, USA) and the level of significance was set at $p<0.05$.

\section{Sensitivity analyses}

Sensitivity analysis was performed by extending the competing risks analysis for falls to all strokes in the NSR from 2011 to 2015. Cox Proportional Hazards regression for post-fall survival was also performed on all strokes who suffered low falls from 2011 to 2015.

\section{Ethics approval}

The second last author's Institutional Review Board granted ethical approval for this retrospective study, as required prior to gaining access to data from the NSR and the NTR, which is de-identified prior to release for research, password-protected and access limited to the premises of the National Registry of Diseases Office (NRDO). Consent was not obtained because information was anonymized and de-identified prior to analysis as per the NRDO protocol.

\section{Results}

Of 25,946 patients that entered the NSR between 2011 to $2013,21,824$ (84.1\%) suffered strokes of ischemic aetiology, followed by parenchymal haemorrhage (13.3\%; 3461 patients) and subarachnoid haemorrhage (2.5\%; 635 patients). Among ischemic strokes, 2255 (10.3\%) patients had recorded Rankin scores (Fig. 1 and Table 1).

Patients with mRS recorded had a mean age of 66.6 years and $58.5 \%$ were men. The ethnic composition was reflective of that of the general local population. A large proportion had hypertension (81.5\%) and hyperlipidaemia (91.2\%), as well as diabetes mellitus (42.1\%) or atrial fibrillation (20.3\%). Patients who ever smoked represented $41.4 \%$ of the sample. By the end of 2015, of those who had a recorded mRS, 54 (2.39\%) suffered a low fall while 93 (4.12\%) died. The median mRS was 2 (IQR 1-3). Moderate to severe injuries (AIS $\geq 3$ ) were sustained to the head $(n=4)$, lower extremities $(n=3)$ and spine $(n=1)$.

After adjusting for potential confounders and accounting for deaths, the mRS was associated with falls risk and showed an inverse U-shaped relationship (Table 2 and Fig. 2). Compared to patients with a score of 0 , the subdistribution hazard ratio (SHR) increased to a maximum of 3.42 (95\%CI: $1.21-9.65, p=0.020$ ) for patients with a score of 2 . The SHR then declined to 2.45 (95\%CI: 0.85-7.12, $p=0.098$ ), 2.86 (95\%CI: $0.95-8.61$,

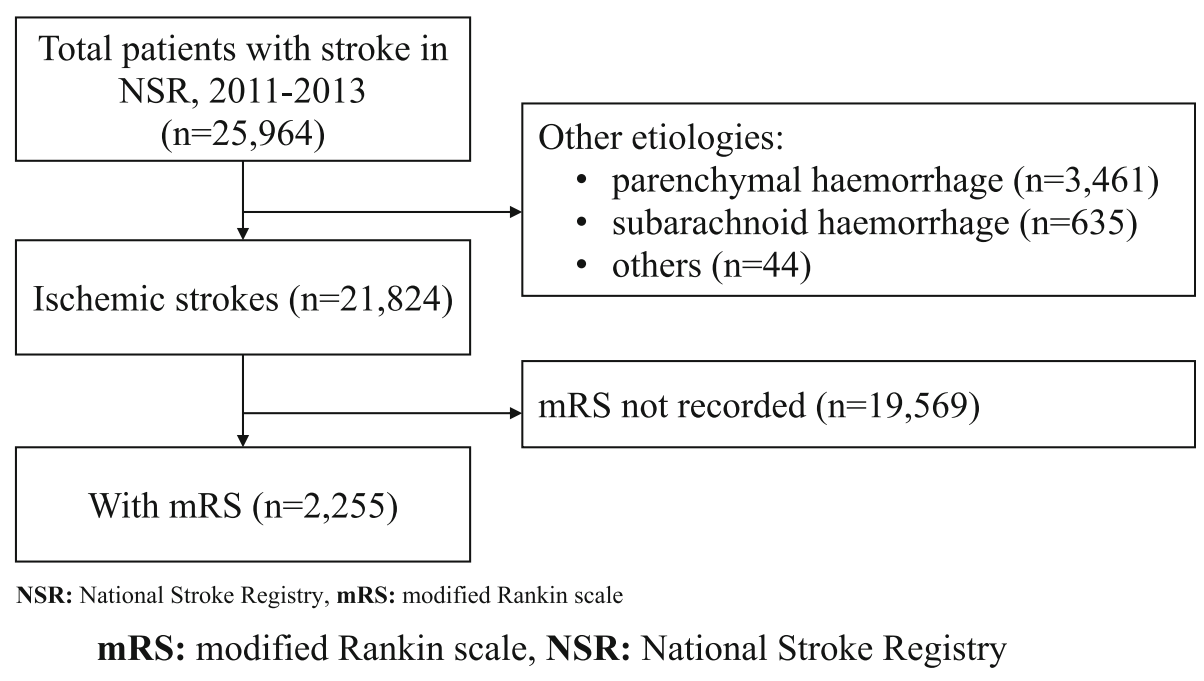

Fig. 1 Study Flow Diagram of Main Analysis. NSR: National Stroke Registry, mRS: modified Rankin scale 
Table 1 Characteristics of Ischemic Stroke Patients in Singapore from 2011 to 2015, With and Without Recorded Modified Rankin Scores

\begin{tabular}{|c|c|c|c|c|c|}
\hline \multirow[t]{2}{*}{ Variables } & \multicolumn{2}{|c|}{ With Rankin Score $(n=2255)$} & \multicolumn{2}{|c|}{ Without Rankin Score $(n=19,569)$} & \multirow[t]{2}{*}{$p$-value } \\
\hline & Frequency & Proportion & Frequency & Proportion & \\
\hline Age (mean, sd) & 66.6 & $(12.8)$ & 67.7 & $(13.3)$ & $<0.001$ \\
\hline Blood Sugar Level, mmol/L (mean, sd) & 8.9 & $(4.47)$ & 9.2 & $(4.67)$ & 0.014 \\
\hline Haemoglobin at Admission, g/dL (mean, sd) & 13.8 & $(1.89)$ & 13.5 & $(2.11)$ & $<0.001$ \\
\hline Gender & & & & & 0.910 \\
\hline Male & 1319 & $58.5 \%$ & 11,472 & $58.6 \%$ & \\
\hline Female & 936 & $41.5 \%$ & 8097 & $41.4 \%$ & \\
\hline Ethnicity & & & & & 0.436 \\
\hline Chinese & 1690 & $74.9 \%$ & 14,858 & $75.9 \%$ & \\
\hline Malay & 389 & $17.3 \%$ & 3120 & $15.9 \%$ & \\
\hline Indian & 146 & $6.5 \%$ & 1331 & $6.8 \%$ & \\
\hline Others & 30 & $1.3 \%$ & 260 & $1.3 \%$ & \\
\hline Smoking & & & & & 0.005 \\
\hline Non-smoker & 1321 & $58.6 \%$ & 11,224 & $57.4 \%$ & \\
\hline Ex-smoker & 281 & $12.5 \%$ & 2800 & $14.3 \%$ & \\
\hline Current-smoker & 628 & $27.8 \%$ & 4893 & $25.0 \%$ & \\
\hline Diabetes Mellitus & 950 & $42.1 \%$ & 8515 & $43.5 \%$ & 0.209 \\
\hline Hypertension & 1838 & $81.5 \%$ & 16,122 & $82.4 \%$ & 0.301 \\
\hline Hyperlipidaemia & 2057 & $91.2 \%$ & 17,668 & $90.4 \%$ & 0.154 \\
\hline Atrial Fibrillation & 458 & $20.3 \%$ & 3874 & $19.8 \%$ & 0.562 \\
\hline History of TIA or Stroke & 324 & $14.4 \%$ & 3963 & $20.3 \%$ & $<0.001$ \\
\hline Anti-platelet at discharge & 1920 & $85.1 \%$ & 16,214 & $82.9 \%$ & 0.006 \\
\hline Anti-coagulant at discharge & 266 & $11.8 \%$ & 1623 & $8.3 \%$ & $<0.001$ \\
\hline Discharge Home & 1563 & $69.3 \%$ & 11,090 & $56.7 \%$ & $<0.001$ \\
\hline On Stroke Pathway & 2110 & $93.6 \%$ & 14,327 & $73.2 \%$ & $<0.001$ \\
\hline \multicolumn{6}{|l|}{ Final Modified Rankin Score $(n=2324)$} \\
\hline 0 & 450 & $20.0 \%$ & & & \\
\hline 1 & 519 & $23.0 \%$ & & & \\
\hline 2 & 379 & $16.8 \%$ & & & \\
\hline 3 & 357 & $15.8 \%$ & & & \\
\hline 4 & 381 & $16.9 \%$ & & & \\
\hline 5 & 169 & $7.5 \%$ & & & \\
\hline Deaths by December 2015 & 93 & $4.1 \%$ & 4051 & $20.7 \%$ & $<0.001$ \\
\hline Sustained a Fall before Death & 0 & $0.0 \%$ & 349 & $1.8 \%$ & $<0.001$ \\
\hline No Fall before Death & 93 & $4.1 \%$ & 3702 & $18.9 \%$ & $<0.001$ \\
\hline Low Falls, Total Number & 54 & $2.4 \%$ & 1996 & $10.2 \%$ & $<0.001$ \\
\hline \multicolumn{6}{|l|}{ Low Falls, By Rankin Score } \\
\hline 0 & 5 & $9.3 \%$ & & & \\
\hline 1 & 10 & $18.5 \%$ & & & \\
\hline 2 & 12 & $22.2 \%$ & & & \\
\hline 3 & 11 & $20.4 \%$ & & & \\
\hline 4 & 12 & $22.2 \%$ & & & \\
\hline 5 & 4 & $7.4 \%$ & & & \\
\hline
\end{tabular}


Table 1 Characteristics of Ischemic Stroke Patients in Singapore from 2011 to 2015, With and Without Recorded Modified Rankin Scores (Continued)

\begin{tabular}{|c|c|c|c|c|c|c|}
\hline \multirow{2}{*}{\multicolumn{2}{|c|}{ Variables }} & \multicolumn{2}{|c|}{ With Rankin Score $(n=2255)$} & \multicolumn{2}{|c|}{ Without Rankin Score $(n=19,569)$} & \multirow[t]{2}{*}{$p$-value } \\
\hline & & Frequency & Proportion & Frequency & Proportion & \\
\hline \multicolumn{7}{|c|}{ Low Falls with a Recorded AIS of 3 or more in:* } \\
\hline \multicolumn{2}{|c|}{ External Region (Skin, exc. burns) } & 0 & $0.00 \%$ & 0 & $0.00 \%$ & - \\
\hline \multicolumn{2}{|l|}{ Face } & 0 & $0.00 \%$ & 0 & $0.00 \%$ & - \\
\hline \multicolumn{2}{|l|}{ Head } & 4 & $0.18 \%$ & 239 & $1.22 \%$ & $<0.001$ \\
\hline \multirow[t]{3}{*}{ Head + AIS $\geq 3$} & On anti-platelet on discharge & 2 & $0.10 \%$ & 104 & $0.64 \%$ & 0.001 \\
\hline & On anti-coagulation on discharge & 0 & $0 \%$ & 14 & $0.86 \%$ & 0.24 \\
\hline & $\begin{array}{l}\text { On anti-platelet or anti-coagulation } \\
\text { on discharge }\end{array}$ & 2 & $0.09 \%$ & 114 & $0.66 \%$ & $<0.001$ \\
\hline \multicolumn{2}{|c|}{ Lower Extremities } & 3 & $0.13 \%$ & 135 & $0.69 \%$ & $<0.001$ \\
\hline \multicolumn{2}{|l|}{ Neck } & 0 & $0.00 \%$ & 1 & $0.01 \%$ & 1.000 \\
\hline \multicolumn{2}{|l|}{ Spine } & 1 & $0.04 \%$ & 19 & $0.10 \%$ & 0.715 \\
\hline \multicolumn{2}{|l|}{ Thorax } & 0 & $0.00 \%$ & 10 & $0.05 \%$ & 0.613 \\
\hline \multicolumn{2}{|c|}{ Upper Extremities } & 0 & $0.00 \%$ & 2 & $0.01 \%$ & 1.000 \\
\hline
\end{tabular}

* AIS: Abbreviated Injury Score; † proportion with denominator as number of persons on relevant anti-thrombotic treatment (i.e. anti-platelet, anticoagulant and either)

$p=0.062)$ and $1.93(95 \%$ CI $0.44-8.52, p=0.38)$ for patients with scores of 3,4 and 5 respectively.

Male gender was associated with reduced falls risk (SHR 0.40, 95\%CI: 0.19-0.84, $p=0.015$ ).

Sensitivity analysis by treating admission haemoglobin levels and blood sugar levels as categorical variables did not alter the associations observed. Antiplatelets and anticoagulants among study patients (patients with mRS recorded) were noted to be associated with greater hazards of falls although this was not statistically significant (antiplatelet SHR 1.30, 95\%CI: $0.36-4.66, p=0.69$; anticoagulation SHR 1.59, 95\%CI: $0.40-6.41, p=0.51$ ). This was further explored with a competing risks analysis for falls performed on all stroke patients $(n=24,344$ stroke survivors with 2234 falls under complete case analysis) which showed that anticoagulation (SHR1.78, 95\%CI 1.48-2.13, $p<0.001$ ) and antiplatelet agents (SHR1.50, $95 \%$ CI $1.30-1.74, \mathrm{p}<0.001)$ were associated with greater risk of recorded falls. However, this analysis did not account for functional status as represented by mRS. Analysis of post-fall survival was also performed on this larger sample $(n=2234$ falls with 559 deaths) which showed that antithrombotic treatment was not associated with worse survival (antiplatelet HR1.05, 95\%CI: 0.80-1.37, $p=0.73$; anticoagulation HR $0.95,95 \% \mathrm{CI}$ 068-1.32, $p=0.74)$.

A similar analysis could not be performed on the sample of patients with recorded Rankin score due to no post-fall deaths observed in this group. Compared to patients without mRS (Table 1), those with recorded scores were more likely to be on anticoagulation $(11.8 \%$ vs $8.3 \%, p<0.001)$, be on the stroke pathway of care $(93.6 \%$ vs $73.2 \%, p<0.001)$ and be discharged home $(69.3 \%$ vs $56.7 \%, p<0.001)$. Those with recorded mRS were also less likely to die by 2015 ( $20.7 \%$ vs $4.1 \%, p<0.001)$, to sustain low falls $(10.2 \%$ vs $2.4 \%, p<0.001)$ and to sustain severe injuries from falls that had AIS of 3 or more (head injury $0.18 \%$ vs $1.22 \%, p<0.001$; lower extremity injury $0.13 \%$ vs $0.69 \%, p<0.001$ ).

\section{Discussion}

We observed an inverse U-shaped relationship between Rankin score and the risk of post-stroke falls. The highest risk was at an mRS of 2. This may be explained by an interplay between exposure to circumstances where falls may occur and one's physiological susceptibility to falls. Persons with low functional status are less likely to be mobile, are more likely to be physically inactive and hence are exposed to fewer circumstances where they may sustain a fall. On the other hand, persons with higher functional states are more likely to have intact motor and sensory functions for maintaining balance, and hence less likely to fall. Persons with moderate functionality experience a mix of these. They have an impaired ability to maintain balance yet retain some reasonable mobility, and thus attempt to be mobile. This may explain why persons in the middle of the spectrum of physical function are most prone to falls.

This finding corroborates with what has been found in three other studies which showed a similar relationship between function and post-stroke falls [17-19]. Two of these studies are well-powered and utilised cohort study designs $[17,18]$, one of which used a large registry-based cohort with data on long-term outcomes [17]. In 
Table 2 Competing Risks Analysis Showing Factors Associated with Sustaining a Recorded Fall After Having an Ischemic Stroke

\begin{tabular}{|c|c|c|c|}
\hline Variables & SHR & $95 \% \mathrm{Cl}$ & $p$-value \\
\hline \multicolumn{4}{|l|}{ Final Modified Rankin Score } \\
\hline 0 & Referent & & \\
\hline 1 & 1.87 & $(0.63,5.50)$ & 0.256 \\
\hline 2 & 3.42 & $(1.21,9.65)$ & 0.020 \\
\hline 3 & 2.45 & $(0.85,7.12)$ & 0.098 \\
\hline 4 & 2.86 & $(0.95,8.61)$ & 0.062 \\
\hline 5 & 1.93 & $(0.44,8.52)$ & 0.383 \\
\hline Age (year) & 1.01 & $(0.99,1.04)$ & 0.366 \\
\hline Blood Sugar Level (mmol/L) & 1.00 & $(0.92,1.08)$ & 0.912 \\
\hline $\begin{array}{l}\text { Haemoglobin at Admission } \\
(\mathrm{g} / \mathrm{dL})\end{array}$ & 0.95 & $(0.83,1.10)$ & 0.505 \\
\hline \multicolumn{4}{|l|}{ Gender } \\
\hline Female & Referent & & \\
\hline Male & 0.40 & $(0.19,0.84)$ & 0.015 \\
\hline \multicolumn{4}{|l|}{ Ethnicity } \\
\hline Chinese & Referent & & \\
\hline Malay & 0.45 & $(0.17,1.18)$ & 0.104 \\
\hline Indian & 0.75 & $(0.22,2.50)$ & 0.634 \\
\hline Others & 1.15 & $(0.16,8.41)$ & 0.887 \\
\hline \multicolumn{4}{|l|}{ Smoking } \\
\hline Non-smoker & Referent & & \\
\hline Ex-smoker & 2.23 & $(0.84,5.93)$ & 0.109 \\
\hline Current-smoker & 1.72 & $(0.79,3.76)$ & 0.175 \\
\hline Diabetes Mellitus & 1.45 & $(0.78,2.70)$ & 0.242 \\
\hline Hypertension & 1.26 & $(0.56,2.82)$ & 0.575 \\
\hline Hyperlipidaemia & 1.59 & $(0.47,5.33)$ & 0.455 \\
\hline Atrial Fibrillation & 0.71 & $(0.31,1.62)$ & 0.412 \\
\hline History of TIA or Stroke & 1.30 & $(0.68,2.49)$ & 0.431 \\
\hline Anti-platelet at discharge & 1.30 & $(0.36,4.66)$ & 0.687 \\
\hline Anti-coagulant at discharge & 1.59 & $(0.39,6.41)$ & 0.514 \\
\hline Discharge Home & 1.44 & $(0.77,2.69)$ & 0.252 \\
\hline
\end{tabular}

contrast, most other studies demonstrate that worse disability and function are associated with increased falls risk [5, 20, 21]. These studies often dichotomize physical function [21, 22] or analyse functional scores as continuous variables on a linear model [20] which may obscure this observation. Future studies may assess if patterns of falls (e.g. mechanism of fall, location) sustained by patients differ between functional levels. Targeted interventions could be potentially developed based on these and evaluated.

The potential positive association between antithrombotic therapy (anticoagulation and antiplatelets) and falls likely arises from a bias in the detection of falls. Patients on antithrombotic therapy who fall are managed with greater caution due to greater risks of haemorrhage and are more likely to undergo brain scans and receive inpatient care $[23,24]$. Also, these patients may be more likely to present for medical attention for falls due to precautions advised in case of trauma while on antithrombotic therapy. We are further reassured that neither agents were associated with worse post-fall survival in the sensitivity analysis. Of note, only $4(0.18 \%)$ of the patients with modified Rankin score sustained a head injury with AIS score of 3 or more during the study period, and of all the ischemic stroke survivors in the registry, only $243(1.1 \%)$ sustained a head injury with an AIS score of 3 or more. Concerns that anti-coagulation may lead to major intracranial haemorrhage after a fall are allayed by the low incidence of serious head injuries and the no-worse survival profile.

\section{Limitations and strengths}

The injurious fall rate in our study is $2.4 \%$, much lower than the proportion of all fallers among community stroke survivors observed in other studies ranging between 23.0 and $55.0 \%$ [5] in the literature. This is because the NTR captures only falls leading to emergency department presentations, capturing significant incidents but is not representative of all falls. In contrast, most studies use self-reported fall outcomes either through interviews or diaries $[5,25]$, which would detect minor falls not picked up by the NTR. In this respect, this study complements the literature on prospective falls, by focusing on falls serious enough to present to hospital. However, it also carries the limitation of omitting nearmiss falls or seemingly minor falls, events that are known to have implications for frailty and future falls.

In the multivariable regression model, 15 individual factors were included for being established risk factors for falls. While this may risk over-fitting with the additional variables, the explanatory model maintains the inverted U-shaped trend (in relation to $\mathrm{mRS}$ ) observed in the univariate analysis (Table 1) and confirms that the trend is not due to confounding.

A low proportion of all stroke patients within the registry had $\mathrm{mRS}$ recorded (10.3\%). There was a significant baseline difference in the history of TIA or stroke (14.4\% vs $20.3 \%$ ), a small but statistically significant difference in age (66.6 years vs 67.7 years), but no significant differences in haemoglobin levels at admission and cardiovascular co-morbidities (diabetes mellitus, hypertension, hyperlipidaemia and atrial fibrillation).

Of note, the patients with recorded mRS included in our analysis were different from those without mRS in several ways. Patients in our study, who had a complete mRS, were more likely to be on a stroke pathway $(93.6 \%$ vs $73.2 \%$ ) than those that were excluded, and more likely 


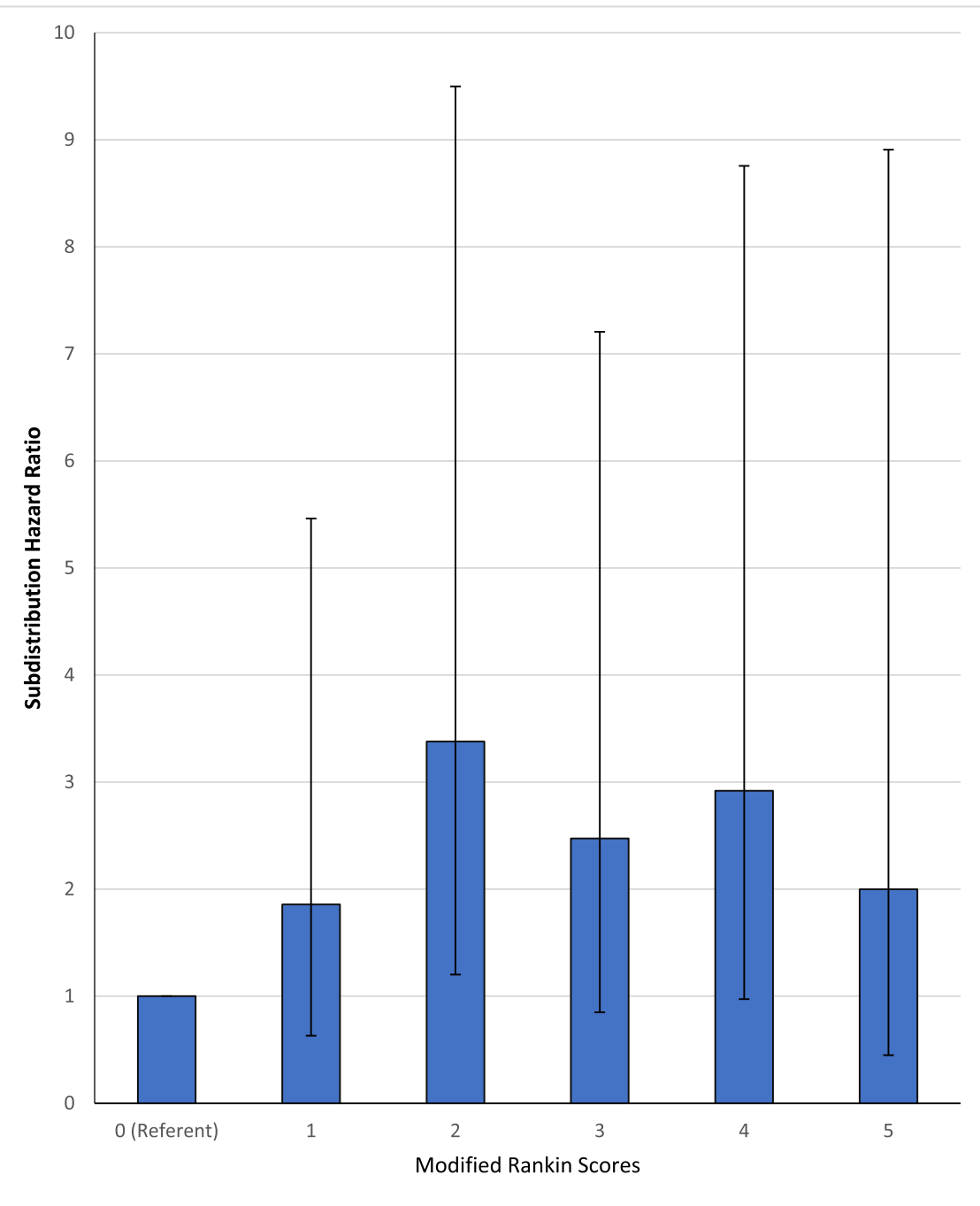

Modified Rankin Score

Fig. 2 Subdistribution Hazard Ratios of Sustaining a Fall After an Ischaemic Stroke, by Modified Rankin Score

to be discharged home. They also had a lower mortality ( $4.1 \%$ vs $20.7 \%)$, and lower risks of falls (2.4\% vs $10.2 \%)$, suggesting that there were uncaptured baseline differences in other co-morbidities and functional status that contributed to differences in outcome.

These differences could explain why, at discharge, they were more likely to receive antiplatelet agents $(85.1 \%$ vs $82.9 \%)$ or oral anticoagulation $(11.8 \%$ vs $8.3 \%)$ than the patients missing mRS. Furthermore, patients missing mRS might include patients assessed by clinicians to have higher fall risk or lower mortality benefit, patients with poor compliance to anticoagulation follow-up and patients who might also not be compliant to rehabilitation follow-up where the mRS would be scored. Another explanation is that patients missing mRS likely included patients with subclinical stroke diagnosed incidentally when presenting for another medical problem, or those presenting with multiple medical issues, hence accounting for the much lower proportion treated in stroke units. Hence, our study findings may be generalizable primarily to patients presenting with acute stroke as the main presenting complaint, and less generalizable to patients where stroke is not their primary presenting complaint, as they were more likely to be missing $\mathrm{mRS}$ in our registry and excluded from our study.

Another potential bias comes from the timing of the score. As scoring of functional status is commonly done in rehabilitation [26], the sample may select for persons who are deemed more appropriate for rehabilitation and may reflect better health and prognosis. Finally, as with 
all registry-based studies, we were only able to include risk factors in our model that were mandated in the registries used.

The strengths are that we used nation-wide registry data involving multiple centres with a large number of patients, with data from a 5-year period.

\section{Conclusions}

An inverse U-shaped relationship between functional status and falls risk was observed. This is consistent with the interplay between decreasing mobility (hence opportunities of falling) and increasing susceptibility to falls. Across mRS scores, patients with a score of 2 have the highest risk of falls and are important candidates for preventive intervention.

\section{Abbreviations}

AIS: Abbreviated Injury Score; HR: Hazard ratio; mRS: Modified Rankin scale; NRDO: National Registry of Diseases Office; NSR: National Stroke Registry; NTR: National Trauma Registry; SHR: Sub-distribution hazard ratio

\section{Acknowledgements}

The authors would like to thank our colleagues that contribute to and maintain the National Trauma Registry and the National Stroke Registry, including the advisory committees, working groups, clinical units, database coordinators, and colleagues at the National Registry of Diseases Office. The collection and management of data for the National Trauma Registry and the National Stroke Registry is funded by the Ministry of Health, Singapore.

\section{Authors' contributions}

All authors meet the criteria for authorship stated in the Uniform Requirements for Manuscripts Submitted to Biomedical Journals. Authors' specific areas of contributions are: Study concept and design: THW: Acquisition of data: N.A. (national registry data). Analysis and interpretation of data: JY, WEW, THW, GHL, DBM, NV, DADS, HMC, SHYY, SJS; Drafting of the manuscript: WEW, THW; Critical revision of the manuscript for important intellectual content: THW, NV, DBM, DADS, HMC, SHYY, SJS. All authors have approved the submitted version and have agreed to be accountable for the accuracy and integrity of the work.

\section{Funding}

This research did not receive any specific funding from agencies in the public, commercial, or not-for-profit sectors.

\section{Availability of data and materials}

The data that support the findings of this study are available from the National Registry of Diseases Office in Singapore, but restrictions apply to the availability of these data, which were used under license for the current study, and so are not publicly available. Data are however available from the authors upon reasonable request and with permission of the National Registry of Diseases Office, Singapore.

\section{Ethics approval and consent to participate}

The Singapore General Hospital Institutional Review Board granted ethical approval for this retrospective study (reference number 201501-00041), as required prior to gaining access to data from the National Stroke Registry and the National Trauma Registry, which is de-identified prior to release for research, password-protected and access limited to the premises of the $\mathrm{Na}$ tional Registry of Diseases Office. Consent was not obtained because information was anonymized and de-identified prior to analysis as per the National Registry of Diseases Office protocol.

\section{Consent for publication}

Not applicable.

\section{Competing interests}

The authors declare that they have no competing interests.

\section{Author details}

${ }^{1}$ Health Services Research Unit, Singapore General Hospital, Level 4, 226 Outram Road, Singapore 169039, Singapore. ${ }^{2}$ Department of Neurology (Singapore General Hospital Campus), National Neuroscience Institute, Singapore General Hospital, Outram Road, Singapore 169608, Singapore. ${ }^{3}$ Duke-NUS Medical School, Singapore, 8 College Road, Singapore 169857, Singapore. ${ }^{4}$ Saw Swee Hock School of Public Health, National University of Singapore, 12 Science Drive 2, \#10-01, Singapore 117549, Singapore. ${ }^{5}$ Health Services \& Systems Research, Duke-National University of Singapore Medical School, Singapore, 8 College Road, Singapore 169857, Singapore. ${ }^{6}$ Center for Clinical Health Policy, Duke University Medical Center, Durham, North Carolina, USA. 'D Duke University Medical Center, Durham, North Carolina 27710, USA. ${ }^{8}$ Department of Rehabilitation Medicine, Changi General Hospital, 2 Simei Street 3, Singapore 529889, Singapore. ${ }^{9}$ Health Promotion Board, 3 Second Hospital Avenue, Singapore 168937, Singapore.

${ }^{10}$ Department of General Surgery, Singapore General Hospital, General Hospital, Outram Road, Singapore 169608, Singapore. ${ }^{11}$ Raffles Neuroscience Centre, Raffles Hospital, Level 9, 585 North Bridge Road, Singapore 188770, Singapore.

Received: 3 June 2019 Accepted: 8 December 2019

Published online: 26 December 2019

\section{References}

1. Wagner LM, Phillips VL, Hunsaker AE, Forducey PG. Falls among communityresiding stroke survivors following inpatient rehabilitation: a descriptive analysis of longitudinal data. BMC Geriatr. 2009;9(1):46

2. Schmid AA, Rittman M. Consequences of poststroke falls: activity limitation, increased dependence, and the development of fear of falling. Am J Occup Ther. 2009;63(3):310-6

3. Batchelor FA, Mackintosh SF, Said CM, Hill KD. Falls after Stroke. Int J Stroke [Internet]. 2012;7(6):482-90. Available from. https://doi.org/10.1111/j.17474949.2012.00796.x

4. Walsh M, Galvin R, Horgan NF. Fall-related experiences of stroke survivors: a meta-ethnography. Disabil Rehabil. 2017;39(7):631-40.

5. Xu T, Clemson L, O'Loughlin K, Lannin NA, Dean C, Koh G. Risk factors for falls in community stroke survivors: a systematic review and meta-analysis. Arch Phys med Rehabil. 2018;99(3):563-573.e5. Available from: https://doi. org/10.1016/j.apmr.2017.06.032

6. Quinn TJ, Dawson J, Walters MR, Lees KR. Functional outcome measures in contemporary stroke trials. Int J stroke. 2009;4(3):200-205. Available from: https://doi.org/10.1111/j.1747-4949.2009.00271.x

7. Maeda N, Urabe Y, Murakami M, Itotani K, Kato J. Discriminant analysis for predictor of falls in stroke patients by using the berg balance scale. Singapore Med J. 2015;56(5):280-3.

8. Pinto EB, Nascimento C, Marinho C, Oliveira I, Monteiro M, Castro M, et al. Risk factors associated with falls in adult patients after stroke living in the community: baseline data from a stroke cohort in Brazil. Top Stroke Rehabil. 2014;21(3):220-7.

9. Khorgami Z, Fleischer WJ, Chen YA, Mushtaq N, Charles MS, Howard CA Ten-year trends in traumatic injury mechanisms and outcomes: a trauma registry analysis. Am J Surg [Internet]. 2018;215(4):727-34 Available from: http://www.sciencedirect.com/science/article/pii/S0002961017314381.

10. Wong TH, Nguyen HV, Chiu MT, Chow KY, Eng M, Ong MEH, et al. The low fall as a surrogate marker of frailty predicts long-term mortality in older trauma patients. PLoS One. 2015;10(9):1-14.

11. Demura S, Yamada T, Kasuga K. Severity of injuries associated with falls in the community dwelling elderly are not affected by fall characteristics and physical function level. Arch Gerontol Geriatr [Internet]. 2012;55(1):186-9 Available from: https://doi.org/10.1016/j.archger.2011.06.033.

12. National Registry of Diseases Office. Singapore Stroke Registry Annual Report 2017 [Internet]. Singapore; 2019. Available from: https://www.nrdo. gov.sg/docs/librariesprovider3/default-document-library/ssr-web-report-201 7.pdf?sfvrsn=7cf41ad3_0

13. Wong TH, Krishnaswamy G, Nadkarni NV, Nguyen H V, Lim GH, Bautista $D C T$, et al. Combining the new injury severity score with an anatomical polytrauma injury variable predicts mortality better than the new injury severity score and the injury severity score: a retrospective cohort study. Scand J Trauma Resusc Emerg Med [Internet]. 2016 Mar;24:25. Available from: https://doi.org/10.1186/s13049-016-0215-6 
14. Venketasubramanian N, Chang HM, Chan BPL, Young SH, Kong KH, Tang KF, et al. Countrywide stroke incidence, subtypes, management and outcome in a multiethnic Asian population: the Singapore stroke registry methodology. Int I Stroke. 2015;10(5):767-9.

15. Spaniolas K, Cheng JD, Gestring ML, Sangosanya A, Stassen NA, Bankey PE. Ground level falls are associated with significant mortality in elderly patients. J Trauma Acute Care Surg. 2010;69(4):821-5.

16. Beck B, Cameron P, Lowthian J, Fitzgerald M, Judson R, Gabbe BJ. Major trauma in older persons. BJS Open [Internet]. 2018;2(5):310-8. Available from:. https://doi.org/10.1002/bjs5.80.

17. Foster EJ, Barlas RS, Bettencourt-Silva JH, Clark AB, Metcalf AK, Bowles KM, et al. Long-term factors associated with falls and fractures poststroke. Front Neurol. 2018;9(APR).

18. Callaly EL, Ni Chroinin D, Hannon N, Sheehan O, Marnane M, Merwick A, et al. Falls and fractures 2 years after acute stroke: the North Dublin population stroke study. Age Ageing. 2015;44(5):882-6.

19. Lim JY, Jung SH, Kim W-S, Paik N-J. Incidence and risk factors of poststroke falls after discharge from inpatient rehabilitation. PM R. 2012 Dec;4(12):945-53.

20. Minet $L R$, Peterson $E$, Von Koch $L$, Ytterberg C. Occurrence and predictors of falls in people with stroke: six-year prospective study. Stroke. 2015;46(9):2688-90.

21. van der Kooi E, Schiemanck SK, Nollet F, Kwakkel G, Meijer JW, van de Port I. Falls are associated with lower self-reported functional status in patients after stroke. Arch Phys med Rehabil [internet]. 2017:98(12):2393-2398. Available from: https://doi.org/10.1016/j.apmr.2017.05.003.

22. Chin LF, Wang JYY, Ong CH, Lee WK, Kong KH. Factors affecting falls in community-dwelling individuals with stroke in Singapore after hospital discharge. Singapore med J [internet], Available from. 2013;54(10):569-75 http://www.ncbi.nlm.nih.gov/pubmed/24154582.

23. Nearing Kl, Tsao JW. Head injury while on anticoagulation: Small numbers, big risks. Neurol Clin Pract [Internet]. 2017;7(4). Available from: http:/cp. neurology.org/content/7/4/280.

24. Beynon C, Hertle DN, Unterberg AW, Sakowitz OW. Clinical review: Traumatic brain injury in patients receiving antiplatelet medication. Crit Care. 2012;16(228)

25. Lamb SE, Ellen ÃCJ, Hauer ÃK, Jorstad-Stein EC, Hauer K, Becker C. Development of a common outcome data set for fall injury prevention trials: the prevention of falls network Europe consensus. J Am Geriatr Soc. 2005;53(9):1618-22.

26. Harrison JK, McArthur KS, Quinn TJ. Assessment scales in stroke: Clinimetric and clinical considerations. Clin Interv Aging. 2013;8:201-11.

\section{Publisher's Note}

Springer Nature remains neutral with regard to jurisdictional claims in published maps and institutional affiliations.

Ready to submit your research? Choose BMC and benefit from:

- fast, convenient online submission

- thorough peer review by experienced researchers in your field

- rapid publication on acceptance

- support for research data, including large and complex data types

- gold Open Access which fosters wider collaboration and increased citations

- maximum visibility for your research: over $100 \mathrm{M}$ website views per year

At $\mathrm{BMC}$, research is always in progress.

Learn more biomedcentral.com/submissions 